\title{
Magnesium sulfate treatment for juvenile ferrets following induction of hydrocephalus with kaolin
}

\author{
Domenico Luciano Di Curzio ${ }^{1,2^{*}}$, Emily Turner-Brannen ${ }^{1,2}$, Xiaoyan Mao ${ }^{1,2}$, Marc Del Bigio ${ }^{1,2}$ \\ From Hydrocephalus 2015 \\ Banff, Canada. 18-21 September 2015
}

\section{Introduction}

Hydrocephalus is characterized by altered cerebrospinal fluid flow increasing brain ventricular cavities. Rodent studies showed that axonal pathology includes calciummediated proteolysis, which can be reduced by the calcium channel antagonist magnesium sulfate (MgSO4). Hydrocephalic ferrets show similar neurological changes as rodents and humans, and thus $\mathrm{MgSO} 4$ treatment was tested in juvenile ferrets.

\section{Methods}

Fourteen-day old ferrets were given kaolin injections into the cisterna magna. Magnetic resonance imaging was performed two weeks later to assess ventricle size and stratify ferrets into treatment groups. Ferrets were treated for two weeks with $\mathrm{MgSO} 4$ or saline, and then imaged before sacrifice. Behaviour was examined thrice weekly. Histological and biochemical assays were also performed.

\section{Results}

Compared to controls, hydrocephalic ferrets were not appreciably different in terms of weight and behaviour; however, those receiving $\mathrm{MgSO} 4$ weighed less, were more lethargic, and displayed reduced activity than those receiving saline. Hydrocephalic ferrets developed ventriculomegaly, but there were no differences for either treatment group. They also exhibited cerebral thinning, decreased depth of cerebral sulci, and rarefaction and fragmentation of periventricular white matter. Though glial fibrillary acidic protein content was elevated in saline treated ferrets, indicative of reactive astroglial changes, there were no significant differences compared to $\mathrm{MgSO} 4$ treated ferrets nor to controls.
Myelin basic protein content and myelin enzyme activity also displayed no significance differences between treatment groups.

\section{Conclusions}

Hydrocephalus-induced disturbances are not ameliorated by MgSO 4 treatment. This suggests that unlike rodents, hydrocephalic ferrets do not experience behavioural improvements nor white matter protection from $\mathrm{MgSO} 4$ therapy, which may be the case for humans with even more complex brains.

\section{Authors' details}

${ }^{1}$ University of Manitoba, Canada. ${ }^{2}$ Children's Hospital Research Institute of Manitoba, Canada.

\section{Published: 18 September 2015}

\section{References}

1. Di Curzio DL, Buist RJ, Del Bigio MR: Reduced subventricular zone proliferation and white matter damage in juvenile ferrets with kaolininduced hydrocephalus. Experimental Neurology 2013, 248:112-128, doi: 10.1016/j.expneurol.2013.06.004.

2. Di Curzio DL, Turner-Brannen E, Del Bigio MR: Oral antioxidant therapy for juvenile rats with kaolin-induced hydrocephalus. Fluids and Barriers of the CNS 2014, 11:23, doi: 10.1186/2045-8118-11-23.

\section{doi:10.1186/2045-8118-12-S1-P28}

Cite this article as: Di Curzio et al:: Magnesium sulfate treatment for juvenile ferrets following induction of hydrocephalus with kaolin. Fluids and Barriers of the CNS 2015 12(Suppl 1):P28. 